\title{
Arginine Vasopressin Response to an Osmotic Stimulus in the Fetal Sheep
}

\author{
RICHARD E. WEITZMAN, ${ }^{(19)}$ DELBERT A. FISHER, JEAN ROBILLARD, ALLAN ERENBERG, \\ ROLAND KENNEDY, AND FRED SMITH
}

Departments of Medicine and Pediatrics, UCLA-Harbor General Hospital, Torrance, California, and Department

of Pediatrics and Anesthesia, University of Iowa, Iowa City, Iowa, USA

\section{Summary}

Baseline plasma osmolality (pOsm) and plasma arginine vasopressin (pAVP) were measured in chronically catheterized fetal sheep. Mean baseline pAVP in fetuses from 101-120 days was $1.9 \pm 0.46 \mu \mathrm{U} / \mathrm{ml}$ (mean \pm SEM) with a pOsm of $293 \pm$ $1.8 \mathrm{mOsm} / \mathrm{kg}$. In fetuses of 121-141 days of gestation, mean pA VP was significantly lower, $0.77 \pm 0.19 \mu \mathrm{U} / \mathrm{ml}(P<0.05)$, with a similar pOsm $(293 \pm 1.9 \mathrm{mOsm} / \mathrm{kg})$. The logarithmic baseline pAVP values were linearly correlated with pOsm for both groups. Hypertonic saline infusion resulted in a similar increase in the $\log$ pAVP corrected for the rise in pOsm in the 101-120-day fetuses and in 121-141-day fetuses. The slope of this response was similar to that of the steady state relationship. The data indicates that the fetal osmoreceptor system for control of arginine vasopressin secretion is fully functional in the last trimester of pregnancy.

\section{Speculation}

The fetal hypothalamic posterior pituitary system appears to show a relatively heightened response to increases in plasma osmolality during the last trimester of gestation. This may reflect the heightened hypothalamic activity postulated to explain the high circulating growth hormone levels at this time. The higher baseline plasma vasopressin levels in the younger fetuses would support this view. Alternatively, the augmented responsiveness may represent an adaptive response to the immaturity of the fetal kidney with respect to free water clearance or an adaptive response to some extrarenal function of the hormone on salt and water homeostasis in utero.

Vasopressin secretion is regulated by two systems of receptors: the osmoreceptors located in or near the supraoptic nuclei in the hypothalamus and a series of volume receptors, including left atrial stretch receptors and carotid sinus and aortic arch baroreceptors. Available information suggests that the newborn is capable of secreting vasopressin at birth and that both the osmoreceptor and volume control systems are functional (3-6). Data regarding fetal vasopressin physiology, however, are meager. Vasopressin has been identified in the human fetal pituitary at $10-12$ weeks of gestation $(9,12)$ and in the fetal pituitary of other mammalian species, including the guinea pig, sheep, and seal, during the last half of gestation $(1,2,10,12,14)$. In addition, in the sheep and monkey, significant concentrations of circulating vasopressin have been detectable in fetal blood during the last half of gestation $(1,11)$, and increases in circulating levels have been evoked either by osmolar or volume (hemorrhage) stimuli $(1,11)$. However, little is known about the sensitivity and relative responsiveness of the fetal osmoreceptor control system. The present studies were designed to provide this information.

\section{MATERIALS AND METHODS}

Pregnant Columbia or Columbia-Suffolk ewes were obtained from a local source and the gestational age based on the induced ovulation technique (7). The animals were maintained in the vivarium and fasted $48 \mathrm{hr}$ before surgery. The pregnant ewes were anesthetized using a mixture of $40 \%$ oxygen and $4 \%$ halothane given by endotracheal tube. After induction, the concentration of halothane was reduced to $0.5-1 \%$. A uterotomy was performed using a sterile technique and the hind leg of the fetus extracted with tension through the uterotomy wound to prevent excessive amniotic fluid loss. PE 50-90 polyvinyl catheters were inserted into the femoral vein and artery and secured with 1 drop of methyl-2-cyanoacrylate (Eastman 910 adhesive, Eastman Chemical Products, Inc., Kingsport, TN). Thereafter, catheters were filled with heparin solution and sealed with special sterile stopcocks or stainless steel pins. The fetus was then returned to the uterine cavity and the uterine incision closed with the fetus advanced into the uterus. The maternal-abdominal wall was closed in three layers and the three catheters were brought out through skin tunnels in the lateral abdominal wall and secured in a small plastic pouch attached to the back of the ewe. The maternal-abdominal wound was closed and animals were maintained on ampicillin 4-5 days postoperatively and were fed the standard sheep chow.

Animals were studied 5 or more days postoperatively and arterial oxygen tension, $\mathrm{pH}$, and glucose were constantly monitored. No animals were studied unless all of these measurements were normal. A total of 16 animals is included in the present study. Serial studies were conducted in the same animals. A total of 18 studies was conducted between 101 and 120 days and 12 between 120 and 141 days of gestation (term $=145$ days).

In each study serial fetal blood samples were obtained before and after the infusion of $7-20 \mathrm{ml} / \mathrm{kg} 5 \% \mathrm{NaCl}$. Fetal weight was estimated from tables of weight versus gestational age. Actual $5 \% \mathrm{NaCl}$ infusion volumes varied from $14-31 \mathrm{ml}$ and the duration of infusion usually ranged from 1-4 min; in three instances infusion time ranged from 7-20 min. Fetal and maternal blood were obtained before infusion and fetal blood samples $(3 \mathrm{ml})$ were obtained at $3,6,9,15,30,60,90$, and $120 \mathrm{~min}$ after beginning the saline infusions. In separate studies removal of as much as $30 \mathrm{ml}$ produced no significant change in plasma AVP even in the early gestational age fetuses. A second maternal sample was obtained $60 \mathrm{~min}$ after beginning the fetal saline infusion.

All blood samples were collected in chilled tubes containing potassium EDTA and were centrifuged within a few minutes; 1-ml plasma aliquots were frozen for AVP measurements. Osmolality was measured in separate aliquots by freezing point depression employing a Fiske osmometer. Within 6 weeks, frozen samples were shipped air freight in Dry Ice to Torrance, CA for extraction and AVP assay. Extraction was performed 
using the bentonite procedure of Skowsky et al. (13). AVP was measured by radioimmunoassay using a slight modification of the method described earlier (13). Antiserum R-71 was employed; this antiserum is specific for AVP and has no cross reactivity with arginine vasotocin.

\section{RESULTS}

The mean baseline plasma AVP in fetuses from 101-120 ( $n$ $=19$ ) days was $1.90 \pm 0.46 \mu \mathrm{U} / \mathrm{ml}$ with a plasma osmolality of $293 \pm 1.8 \mathrm{mOsm} / \mathrm{kg}$. In fetuses of 121-141 days of gestational age the mean baseline pAVP $(n=11)$ was significantly lower, $0.77 \pm 0.19 \mu \mathrm{U} / \mathrm{ml}(P<0.05)$, whereas pOsm was similar to that in the younger fetuses $(293 \pm 1.9 \mathrm{mOsm} / \mathrm{kg}$ ) (Table 1$)$.

Paired maternal baseline AVP concentrations were determined in several animals. Between 101 and 120 days of gestation, mean fetal levels were somewhat higher than mean maternal levels; however, the difference was not significant: $1.59 \pm$ $0.44 \mu \mathrm{U} / \mathrm{ml}$ for fetus, $0.84 \pm 0.17 \mu \mathrm{U} / \mathrm{ml}$ for the mothers $(n=$ $12, P>0.05)$. Between 121 days gestation and term $(n=4)$, fetal and maternal levels were similar $(0.68 \pm 0.27 \mu \mathrm{U} / \mathrm{ml}$ and $0.70 \pm 0.22 \mu \mathrm{U} / \mathrm{ml}$, respectively).

A linear regression was calculated for the logarithm of baseline pAVP versus pOsm for the 30 observation periods in the

Table 1. Baseline p AVP concentrations and pOsm and response to hypertonic saline as function of gestational age

\begin{tabular}{lcccc}
\hline & $\begin{array}{c}\text { Baseline } \\
\mathrm{pAVP}, \\
\mu \mathrm{U} / \mathrm{ml}\end{array}$ & $\begin{array}{c}\text { Baseline } \\
\text { pOsm, } \\
\mathrm{mOsm} / \mathrm{kg}\end{array}$ & $\begin{array}{c}\text { log AVP } \\
\text { post-saline } \\
-\log \text { AVP } \\
\text { baseline }\end{array}$ \\
\hline $\begin{array}{l}n \\
101-120 \text { days }\end{array}$ & 19 & $1.90 \pm 0.45$ & $292.9 \pm 1.8$ & $0.035 \pm 0.012$ \\
$\begin{array}{c}121 \text { days to } \\
\text { term }\end{array}$ & 11 & $0.77 \pm 0.19$ & $292.7 \pm 1.9$ & $0.037 \pm 0.010$ \\
Significance & & $P<0.05$ & $P>0.9$ & $P>0.3$ \\
\hline
\end{tabular}

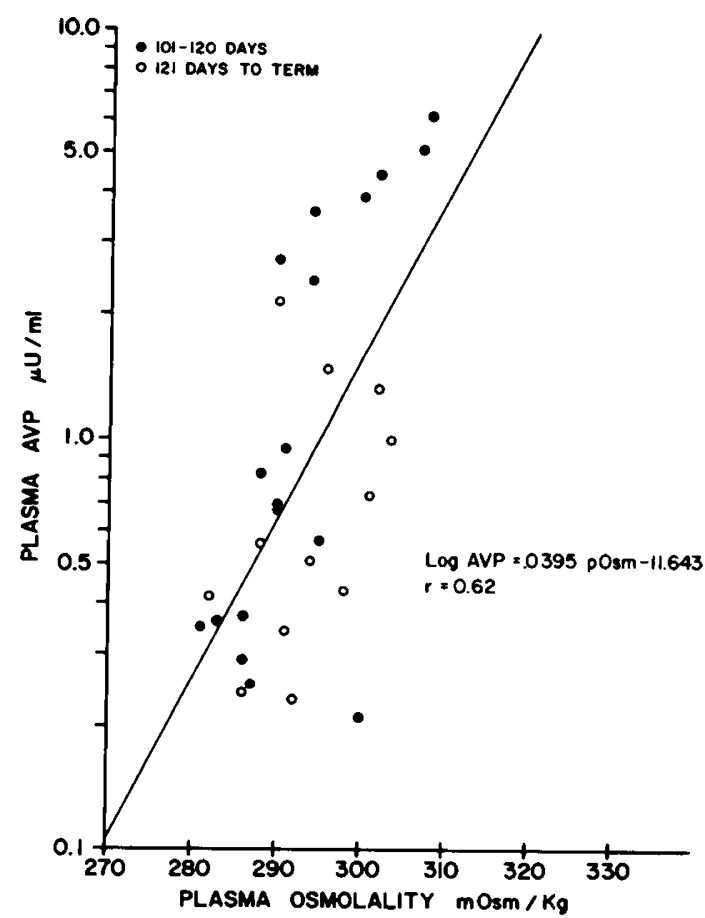

Fig. 1. Log linear relationship between pAVP and pOsm in fetal sheep. : data from fetuses 101-120 days of gestational age; $O$ : data from fetuses 121 days to term.

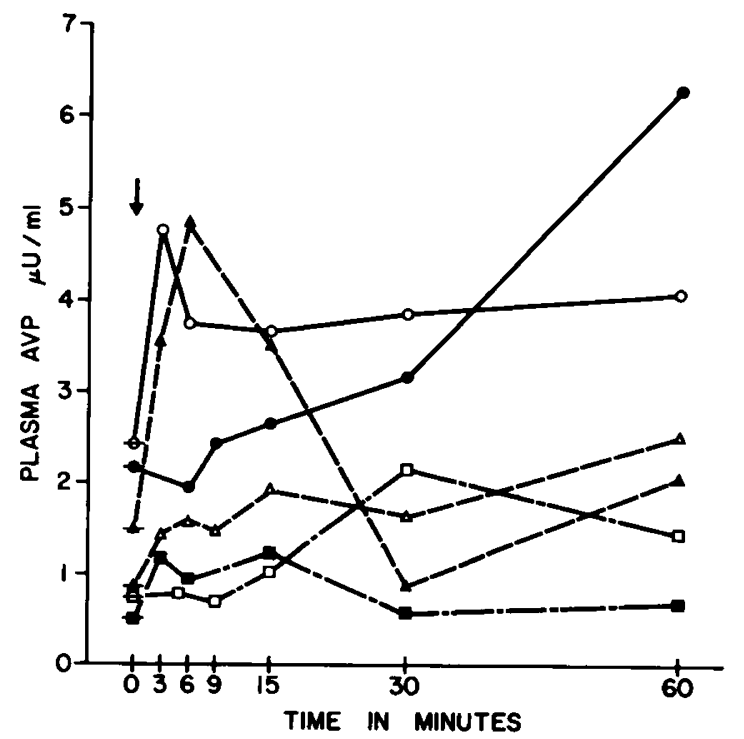

Fig. 2. Time course of response of pAVP to hypertonic saline infusion in six representative experiments. The time of peak pAVP varied from 3-60 min after injection of hypertonic saline.

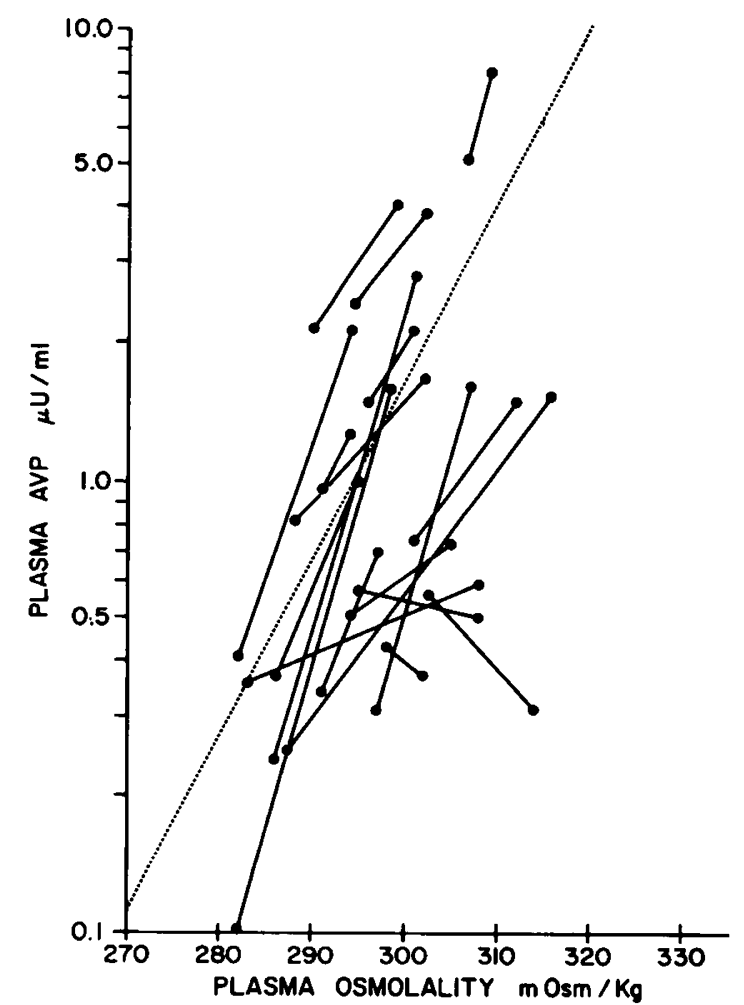

Fig. 3. The log response of pAVP to hypertonic saline infusion. The solid lines connect the baseline $\mathrm{pAVP}$ and $\mathrm{pOsm}$ with the mean pooled pAVP and pOsm values of the 15-, 30-, and 60-min samples. The dotted line represents the regression line for steady state pAVP and pOsm derived from Figure 1.

16 fetuses. This showed a significant correlation $(P<0.001, r$ $=0.62$ ) with log $\mathrm{pAVP}=0.0395$ pOsm -11.643 (Fig. 1).

Plasma AVP was elevated after hypertonic saline infusion in sixteen out of nineteen experiments. The timing of the peak response was somewhat variable (Fig. 2). In some experiments the peak response occurred soon after the saline infusion, but in other experiments it was delayed as long as $60 \mathrm{~min}$ after the injection (Fig. 2). The variable response pattern could not be explained by' variations in osmolality or blood volume. We have 
reported elsewhere that serial blood samples for AVP measurement collected at 3-min intervals after osmotic stimulation show a pattern suggestive of episodic secretion (16). The observed variations in plasma AVP levels could not be accounted for by intraassay variation (less than $8 \%$ ) and could be abolished by water loading. Individual plasma AVP determinations were not highly correlated with plasma osmolality, whereas a high correlation was observed between osmolality and integrated plasma AVP determined over a period of $30 \mathrm{~min}(15,16)$.

Because of the variability in the AVP response, the baseline pAVP and pOsm were compared to the mean pAVP concentration and pOsm derived from the 15-, 30-, and 60-min samples. The interval of $15-60 \mathrm{~min}$ was chosen because of the relatively stable plasma osmolalities during this period. The log baseline AVP concentration was subtracted from the log mean postsaline AVP level. The difference in the logs was then divided by the difference in pOsm. In this fashion the AVP response was normalized for the change in plasma tonicity. Individual responses are plotted in Fig. 3 for comparison with the steady state regression relationship. The mean AVP response slopes were $0.035 \pm 0.012$ for 8 fetuses from 101-120 days of gestation and $0.037 \pm 0.010$ for 11 fetuses from 121 days to term $(P>0.3$, NS). These were quite similar to the slope of the steady state relationship between $\log$ AVP and pOsm (0.0395, Fig. 3).

\section{DISCUSSION}

Plasma arginine vasopressin was detected easily in all fetuses studied as early as 103 days of gestation using a sensitive and specific radioimmunoassay. Indeed, mean pAVP concentrations tended to be higher between 101 and 120 days gestation than in older fetuses. Also, the mean fetal AVP level tended to be higher between 101 and 120 days than the mean maternal concentration.

Previous studies of pAVP concentrations in the fetus have shown very high levels obtained after acute fetal catheterization, undetectable levels in chronic fetal preparations in the third trimester, and very high levels just before or after delivery. The more sensitive radioimmunoassay for AVP used in the present study permitted quantification of the low baseline AVP concentrations during the last trimester of gestation. pAVP was always detectable in our fetal preparations. It is also significant that the baseline fetal pAVP levels closely approximated the values obtained in the mothers, and the mean maternal values were similar to those in nonpregnant ewes. This would suggest that in the present fetal preparations the effect of hysterotomy and catheter placement on PAVP was minimal at the time of study. Thus the hypertonic saline challenge was conducted under conditions that approximated physiologic ones.

The relatively higher mean fetal AVP levels in the younger fetuses (Table 2) does not appear to be due to greater stress. The interval between catheterization and study was similar in early and late fetuses and study conditions were identical. It is possible that the higher pAVP levels in the younger fetuses reflect an inherent hypothalamic hyperactivity near midgestation, as postulated by Kaplan et al. (8) to explain the high circulating levels of growth hormone in fetal blood at this time.

A response to hypertonic saline was noted in 7 of 8 fetuses between 101 and 120 days of gestation and in 9 of 11 fetuses

Table 2. Paired fetal and maternal plasma arginine vasopressin concentrations as function of gestational age

\begin{tabular}{ccccc}
\hline & $\begin{array}{c}\text { Fetal, } \\
\mu \mathrm{U} / \mathrm{ml}\end{array}$ & $\begin{array}{c}\text { Maternal, } \\
\mu \mathrm{U} / \mathrm{ml}\end{array}$ & $n$ & Significance \\
\hline $\begin{array}{c}101-120 \\
\text { days }\end{array}$ & $1.59 \pm 0.44$ & $0.843 \pm .17$ & 12 & $P>0.05$ \\
$\begin{array}{c}121 \text { days } \\
\text { to term }\end{array}$ & $0.68 \pm 0.27$ & $0.70 \pm .22$ & 4 & $P>0.05$ \\
\hline
\end{tabular}

after 121 days. The magnitude of response was similar in both groups. Previous studies from our laboratory have shown that there is an exponential relationship between pAVP concentration and pOsm such that the log of pAVP is a linear function of pOsm (15). When the steady state values for pAVP and pOsm for nonpregnant ewes were plotted on semilogarithmic paper, the slope was 0.0282 . The slope of the regression line of log pAVP and pOsm for the fetuses in the present study (0.0395) was somewhat steeper than that in adults, suggesting relatively augmented AVP responsiveness in the fetus for any particular increase in plasma tonicity. The response to hypertonic saline also was expressed in terms of an exponential relationship between pAVP and pOsm. The increase in log pAVP before and after hypertonic saline infusion was divided by the increase in pOsm. This ratio reflects the pAVP response to acute stimulation. The response slope to acute saline challenge closely approximated the slope of the steady state regression and was considerably steeper than the response to hypertonic saline in the adult. This observation would tend to support the concept of enhanced osmoreceptor sensitivity in the fetus, and lends further credence to the higher baseline AVP concentrations in the blood of the younger fetuses.

The present results indicate that osmoreceptor control of AVP release in the fetus is essentially mature during the last trimester of gestation. Relative responsiveness to an osmolar stimulus appears even to be augmented at this time, although the differences between the fetal and adult responses are small. Further studies even earlier in gestation will be necessary to determine the time in gestation when the AVP response first appears. The significance of fetal AVP to water and electrolyte homeostasis and fetal renal function also remains to be defined.

\section{CONCLUSION}

pAVP concentrations were measured in chronically catheterized, unstressed fetal sheep using a sensitive and specific radioimmunoassay. Baseline AVP levels were slightly, although significantly, higher in fetuses from 101-120 days of gestation than in those from 121-141 days or in the paired samples taken from the mothers. A log linear relationship was observed between baseline pAVP and plasma osmolality. Hypertonic saline challenges resulted in increased plasma vasopressin concentration in 7 of 8 fetuses between 101 and 120 days and in 9 of 11 fetuses after 121 days. The magnitude of this response expressed as increase in $\log \mathrm{pAVP} /$ increase in $\mathrm{pOsm}$ was similar to the slope of the steady state relationship. The results indicate that fetal osmoreceptor control of AVP secretion is mature by the third trimester of gestation in fetal sheep and suggest that responsiveness of the system is augmented relative to the adult.

\section{REFERENCES AND NOTES}

1. Alexander, D. P, Britton, H. G., Forsling, M. L., Nixon, D. A., and Ratcliffe, J. G.: Pituitary and plasma concentrations of adrenocorticotro phin, growth hormone, vasopressin and oxytocin in fetal and maternal sheep during the latter half of gestation and the response to hemorrhage. Biol. Neonate, 24: 206 (1974).

2. Burton, A. M., and Forsling, M. L.: Neurohypophyseal hormone content in foetal, newborn and adult guinea pigs. J. Physiol. (London), 221: 6-7P (1972).

3. Chard, T., Hudson, C. N., Edwards, C. R. W., and Boyd, N. R. H.: The release of oxytocin and vasopressin by the human foetus during labor. Nature (London), 234: 352 (1971)

4. Fisher, D. A., Pyle, H. R., Porter, J. C., Beard, A. G., and Panas, T. C.: Studies of control of water balance in the newborn. Amer. J. Dis. Child., 106: 137 (1963).

5. Hoppenstein, J. M., Miltenberger, F. W., and Moran, W. H., Jr.: Antidiuretic hormone blood levels in infants from birth to three months of age. Surg. Forum, 18: 292 (1967).

6. Hoppenstein, J. M., Miltenberger, F. W., and Moran, W. H., Jr.: The increase in blood levels of vasopressin in infants during birth and surgical procedures. Surg. Gynecol. Obstet., 90: 966 (1968).

7. Jenning, J. J., and Crowley, J. P.: The influence of mating management on fertility in ewes following progesterone PMS treatment. Vet. Med., 90: 495 (1972).

8. Kaplan, S. L., Grumbach, M. M., and Shepard, T. H.: The ontogenesis of 
human fetal hormones. J. Clin. Invest., 51: 3080 (1972).

9. Levina, S. E.: Endocrine features in development of human hypothalamus, hypophysis, and placenta. Gen. Comp. Endocrinol., 11: 151 (1968)

10. Perks, A. M. and Vizsolyi,E.: Studies of the neurohypophysis in foetal mammals. In: K. W. Cross, G. S. Davies, and P. W. Nathanielsz: Foetal and Neonatal Physiology, p. 430 (Cambridge University Press, London, 1973).

11. Skowsky, W. R., Bashore, R. A., Smith, F. G., and Fisher, D. A.: Vasopressin metabolism in the foetus and newborn, In: K. W. Cross, G. S. Davies, and P. W. Nathanielsz: Foetal and Neonatal Physiology, p. 439 (Cambridge University Press, London, 1973).

12. Skowsky, W. R., and Fisher, D. A.: Fetal neurohypophyseal arginine vasopression and arginine vasotocin in man and sheep. Pediat. Res., 11: 627 (1977).

13. Skowsky, W. R., Rosenbloom, A., and Fisher, D. A.: Radioimmunoassay of arginine vasopressin development and application. J. Clin. Endocrinol. Metab., 38: 278 (1974)
14. Vizsolyi, E., and Perks, A. M.: New neurohypophyseal principle in foetal mammals. Nature (London), 223: 1169 (1969)

15. Weitzman, R. E., and Fisher, D. A.: Log linear relationship between plasma arginine vasopressin and plasma osmolality. Amer. J. Physiol., 233: E37 (1977).

16. Weitzen, R. E. Fisher, D. A., DiStefano, J. J., III, and Bennett, C. M.: Episodic secretion of arginine vasopressin. Amer.J. Physiol., 233: E32 (1977).

17. Ms. Chris Sessions and Ms. Che-Ching Wang provided excellent technical assistance. Ms. Mary Badenoch prepared the manuscript.

18. This research was supported by USPHS Grants HD-06335 and HD-08953 from NICHHD, NIH.

19. Requests for reprints should be addressed to: Richard E. Weitzman, M.D., Harbor General Hospital, Building A-17, 1000 West Carson Street, Torrance, California 90509 (USA).

20. Received for publication January 7,1977

21. Accepted for publication April 26, 1977.

Printed in U.S.A.

Aminophylline breathing cortisol lung lavage fluid

oxygen

premature

\title{
Effects of Cortisol and Aminophylline upon Survival, Pulmonary Mechanics, and Secreted Phosphatidyl Choline of Prematurely Delivered Rabbits
}

\author{
CYNTHIA T. BARRETT, ${ }^{(26)}$ ALEX SEVANIAN, DALE L. PHELPS, CARL GILDEN, AND \\ SOLOMON A. KAPLAN \\ Department of Pediatrics, UCLA School of Medicine, Los Angeles, California, USA
}

\begin{abstract}
Summary
Rabbits delivered at 27.0 days of gestation were studied after administration of cortisol $(2 \mathrm{mg} / \mathrm{kg} / \mathrm{day})$, aminophylline $(6.25$ $\mathrm{mg} / \mathrm{kg} / \mathrm{day})$, or sterile saline to the does on days 24-26 of gestation. Survival at $60 \mathrm{~min}$ was $52.9 \%$ in the aminophyllinetreated group and $22.2 \%$ in the control and cortisol-treated groups with all animals being in a warm, oxygen-enriched environment and receiving frequent tactile stimulation. Lung volume at $30 \mathrm{~cm} \mathbf{H}_{2} \mathrm{O}$ was lower in the cortisol-treated group than in the controls or aminophylline-treated group in animals surviving for $60 \mathrm{~min}$ (Table 2). The aminophylline-treated group retained significantly more gas at low pressures on the deflation curve (Table 2) and had significantly more phosphatidylcholine recovered in lung lavage fluid (Table 3) than the other groups. Aminophylline appears to have enhanced lung maturation better than cortisol in this experimental model.
\end{abstract}

\section{Speculation}

Improved survival of prematurely delivered rabbits after aminophylline administration (as compared with cortisol) may be due to a combination of factors including enhanced maturation of the lungs as well as stimulation of the respiratory center.

Accelerated maturation of fetal mammalian lungs as evidenced by physiologic and biochemical measurements is now well known to occur after antepartum administration of glucocorticoids. In addition, decreased morbidity from RDS and improved survival of prematurely born human infants has been reported by Liggins and Howie (13) when glucocorticoids have been administered at least $24 \mathrm{hr}$ before delivery. Motoyama and his co-investigators (15) reported that after antenatal administration of glucocorticoids some rabbits delivered at 27 days of gestation were able to breathe, but control animals did not breathe until 28 days. The treated animals, in addition, retained more air at low pressures and had better lung fluid bubble stability than the controls. Taeusch and his coworkers (21) reported increased survival of rabbits delivered at 28 days of gestation in the first $6 \mathrm{hr}$ after delivery after direct fetal administration of hydrocortisone. Lung pressure-volume measurements indicated that lung stability as measured by the percentage of total lung volume retained during deflation at 10 $\mathrm{mm} \mathrm{Hg}$ increased with increasing survival.

Although augmented production of corticosteroids is probably one mechanism by which fetal lungs mature normally, the pharmacologic doses used to stimulate accelerated maturation may have deleterious effects upon the fetuses so treated. Mothers with eclampsia treated with betamethasone have increased antenatal mortality compared with controls (13); animal studies indicate that corticosteroids may compromise placental function (23) and also cause temporary inhibition of lung growth (5, 11). In addition, glucocorticoid administration may be accompanied by reduced cell numbers in the brain and by disturbances of myelination, synaptic growth, and locomotor ability $(9,19)$.

For these reasons our laboratory has been investigating some mechanisms by which corticosteroids accelerate lung maturation in an attempt to identify a pharmacologic agent with less 